\title{
Fenofibrate protects endothelial cells against the harmful effects of TNF-alpha
}

Corli Westcott*, Amanda Genis", Mashudu Mthethwa*, Roxanne Graham*, Derick van Vuuren*, Barbara Huisamen",\# and Hans Strijdom"

\section{"Division of Medical Physiology, Faculty of Medicine and Health Sciences, University of Stellenbosch, Cape Town, South Africa "Biotechnology, Research and Innovation Platform, Medical Research Council,Tygerberg, South Africa.}

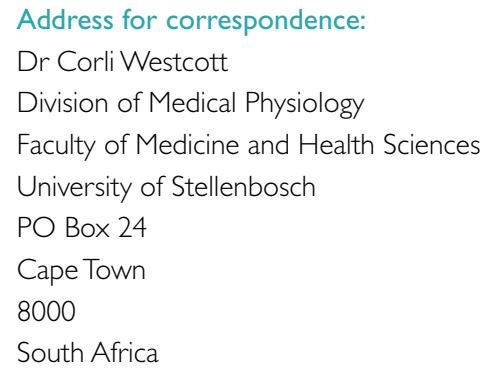

\section{INTRODUCTION}

Fenofibrate, a fibric acid-derivative and peroxisome proliferatoractivated receptor-alpha (PPAR $\alpha$ ) agonist, is best known for its high density lipoprotein cholesterol increasing and triglyceride reducing effects. ${ }^{(1,2)}$ In addition to its anti-dyslipidaemic actions, fenofibrate has been shown to exert several pleiotropic (nonlipid) vasculo-protective effects, including antioxidant, ${ }^{(3-6)}$ antithrombotic, ${ }^{(7,8)}$ and anti-apoptotic effects. ${ }^{(9,10)}$

Many of the beneficial pleiotropic effects of fenofibrate on the vasculature are thought to be driven by increased endotheliumdependent nitric oxide ( $\mathrm{NO}$ ) release, as demonstrated in a study which showed that fenofibrate treatment improved hyperaemia-induced flow-mediated dilatation in patients with hypertriglyceridaemia. ${ }^{(1)} \mathrm{NO}$ is an important endotheliumderived molecule involved in the maintenance of vascular homeostasis,(11) and is synthesised by the NO synthase (NOS) enzyme family, viz. endothelial NOS (eNOS), neuronal NOS (nNOS) and inducible NOS (iNOS). ${ }^{(12)}$ In addition to its $\mathrm{NO}$ modulatory effects, fenofibrate has been shown to possess antioxidant properties. For example, fenofibrate reduced superoxide levels and apoptosis in human umbilical vein endothelial cells (HUVECs) exposed to high glucose treatment, ${ }^{(10)}$ and increased superoxide dismutase activity in rat brain microvessels. ${ }^{(3)}$

\section{ABSTRACT}

Introduction: Fenofibrate exerts pleiotropic effects on endothelial cells (ECs) by, amongst others, increasing nitric oxide (NO) production. We aimed to investigate fenofibrate's putative beneficial actions in healthy or TNF-alpha-induced dysfunctional ECs.

Methods: Fenofibrate-induced pro-vasodilatory responses were assessed in aortic rings $(50$ - 125 $\mu \mathrm{M}$; $30 \mathrm{~min})$ with and without L-NMMA $(100 \mu \mathrm{M})$. Rat cardiac microvascular ECs were treated with fenofibrate (30 and $50 \mu \mathrm{M} ; \mathrm{Ih})$. In the pre-treatment experiments, fenofibrate $(50 \mu \mathrm{M})$ was administered one hour before TNFalpha treatment (20ng/ml; 24h). NO-production (DAF2/DA or Griess assay), mitochondrial ROS-production (MitoSox ${ }^{\mathrm{TM}}$ ), cell viability (propidium iodide staining), and changes in the expression/phosphorylation of critical endothelial proteins were measured by Western blotting.

Results: Fenofibrate increased NO-production $\sim 2$-fold in healthy ECs ( $p<0.05$ vs. vehicle). A $23 \%$ pro-vasodilatory response was induced in aortic rings, which was reversed by L-NMMA ( $p<0.05$ vs. fenofibrate). Fenofibrate pretreatment ameliorated TNF-alpha-induced endothelial dysfunction by reversing the loss of NO, improving oxidative stress, restoring cell viability and preventing caspase-3 activation. Protective effects were underpinned by $\sim 47 \%$ and $\sim 49 \%$ up-regulation of activated eNOS and AMP-kinase, respectively ( $p<0.05$ vs. TNFalpha).

Conclusions: Fenofibrate protects TNF-alpha-induced dysfunctional ECs via up-regulated eNOS-NO, reduced oxidative stress and improved cell viability. These novel findings warrant further investigations to explore the potential use of fenofibrate as an anti-endothelial dysfunction therapeutic agent. SAHeart 20।7;14:22-34

Cardiovascular risk factors, such as diabetes mellitus and obesity, as well as atherosclerosis are associated with inflammation and increased levels of pro-inflammatory cytokines. ${ }^{(13-15)}$ Endothelial cells are important cellular targets of pro-inflammatory cytokines such as tumour necrosis factor alpha (TNF-alpha), ${ }^{(16)}$ and exposure of the endothelium to TNF-alpha can result in endothelial dysfunction. ${ }^{(13)}$ In fact, TNF-alpha is considered one of the main promoters of endothelial dysfunction during the early stages of atherosclerosis. (17) Hence, investigations into potential therapeutic interventions that can prevent TNF-alpha 
induced vascular damage are important. Endothelial dysfunction is characterised by reduced $\mathrm{NO}$ bioavailability and impaired endothelium-dependent vasodilation ${ }^{(18)}$ and is regarded as an early, reversible precursor and predictor of atherosclerosis. ${ }^{(19-20)}$ Although the exact cellular mechanisms underlying TNF-alpha induced endothelial dysfunction are still under scrutiny, ${ }^{(22)}$ oxidative stress is generally recognised as the candidate common mechanism. ${ }^{(23-24)}$

In view of the fact that endothelial dysfunction is potentially reversible, early therapeutic interventions could prevent future cardiovascular disease. Previous studies have investigated the effect of fenofibrate on TNF-alpha induced changes in the vasculature. Zhao and Wu (2004) showed that fenofibrate reduced TNF-alpha levels in the serum of rabbits on a high cholesterol diet as well as TNF-alpha secretion from adipocytes. (26) Furthermore, fenofibrate pre-treatment prior to TNF-alpha administration in HUVECs was able to inhibit TNF-alpha induced expression of cluster of differentiation 40 (CD40).(27-28) Huang, et al. (2009) showed that fenofibrate prevented increases in monocyte adhesion to endothelial cells in TNF-alpha-stimulated human aortic endothelial cells. ${ }^{(29)}$ However, as far as we are aware, no previous studies have investigated whether fenofibrate can protect vascular endothelial cells against the harmful effects of TNF-alpha with regards to $\mathrm{NO}$ production, ROS generation and cell viability. Therefore, the present study aimed to investigate whether pre-treatment with fenofibrate protects adult rat endothelial cells against TNFalpha induced endothelial dysfunction, and if so, whether the protection is associated with the modulation of $\mathrm{NO}$ biosynthesis, ROS generation and markers of cell death.

\section{MATERIALS AND METHODS}

\section{Research materials and reagents}

Endothelial growth medium (Endothelial cell basal medium-2; EBM-2) was purchased from Clonetics (Cambrex Bio Science, Walkersville, USA); 4.5-Diaminofluorescein diacetate (DAF-2/ $D A$ ) and $N^{G}$-Monomethyl-L-arginine monoacetate (L-NMMA) were from Calbiochem (San Diego, California, USA). Attachment factor, trypsin (500 BAEE units trypsin / $80 \mu \mathrm{g}$ EDTA • 4Na per $\mathrm{ml}$ in Dulbecco's PBS), dihydroethidium (DHE) and MitoSox ${ }^{T M}$ Red were from Life Technologies (Carlsbad, California, USA). Fenofibrate, human recombinant TNF-alpha, dihydrorhodamine-123 (DHR-123), dimethoxy-I, 4-naphthoquinone (DMNQ), diethylamine NONOate (DEA/NO), dimethyl sulfoxide (DMSO), acetylcholine, phenylephrine and Griess Reagent were from Sigma-Aldrich (St Louis, Missouri, USA). The following antibodies were from Cell Signaling Technologies (Beverly, Massachusetts, USA): eNOS, phosphorylated-eNOS (Ser 1 177); Akt, phosphorylated Akt (Ser 473); AMP activated protein kinase (AMPK), phosphorylated AMPK (Thr 172); cleaved caspase-3 and IкB $\alpha$. p22PHOX, and nitrotyrosine antibodies were purchased from Santa Cruz Biotechnologies. Propidium iodide (PI) solution and cell staining buffer were purchased from Bio-Legend (Biocom-Biotech, San Diego, California, USA). Enhanced chemiluminescence (ECL) detection reagent, ECL hyperfilm, and Horseradish peroxidaselinked anti-rabbit IgG were from AEC Amersham (Buckinghamshire, UK). Polyvinylidene difluoride (PVDF) membrane (Immobilon ${ }^{\mathrm{TM}} \mathrm{P}$ ) and authentic peroxynitrite were from Millipore (Bedford, MA, USA). Foetal bovine serum was purchased from Highveld Biological (Lyndhurst, South Africa). All other chemicals and buffer reagents were purchased from Merck (Damstadt, Germany).

\section{Adult rat aortic ring studies}

\section{Animal care}

Experiments were conducted according to the "Guide for the care and use of laboratory animals" published by the US National Institutes of Health ( $\mathrm{NIH}$ publication no. 85 - 23, revised 1985) and the South African Bureau of Standards (SANS 10386, 2008). Ethics approval was received from the University of Stellenbosch (Project number: SU-ACUMII 00002). Male Wistar rats weighing 200 - 250g were supplied by the Central Research Facility of the Faculty of Medicine and Health Sciences of Stellenbosch University where they were housed in temperature controlled conditions $\left(22-24^{\circ} \mathrm{C}\right)$. Animals were subjected to a 12 hour light and dark cycle and had free access to standard rat chow and water. Animals were anaesthetised with pentobarbital $(160 \mathrm{mg} / \mathrm{kg}$ ) until deep anaesthesia was reached as evidenced by the lack of a pedal reflex. They were then euthanised by exsanguination before excision of the aortas.

\section{Assessment of aortic vasoactive responses}

The chest cavity was opened by incision and thoracic aorta excised and placed in ice cold Krebs-Henseleit solution, containing sodium chloride $(\mathrm{NaCl}) 119 \mathrm{mM}$, sodium bicarbonate $\left(\mathrm{NaHCO}_{3}\right) 25 \mathrm{mM}$, potassium chloride $(\mathrm{KCl}) 4.75 \mathrm{mM}$, monopotassium phosphate $\left(\mathrm{KH}_{2} \mathrm{PO}_{4}\right) \quad 1.2 \mathrm{mM}$, magnesium sulfate heptahydrate $\left(\mathrm{MgSO}_{4} \cdot 7 \mathrm{H}_{2} \mathrm{O}\right) 0.6 \mathrm{mM}$, sodium sulfate $\left(\mathrm{Na}_{2} \mathrm{SO}_{4}\right)$ $0.6 \mathrm{mM}$, calcium chloride monohydrate $\left(\mathrm{CaCl} 2 . \mathrm{H}^{2} \mathrm{O}\right) 1.25 \mathrm{mM}$, and glucose $10 \mathrm{mM}$. Excess perivascular fat and connective tissue were removed. Aortas were cut into 3 - $4 \mathrm{~mm}$ ring segments that were subsequently mounted onto 2 steel hooks in a $25 \mathrm{ml}$ organ bath (AD Instruments, Bella Vista, New South Wales, Australia) containing oxygenated $\left(95 \% \mathrm{O}^{2}\right.$ and $\left.5 \% \mathrm{CO}^{2}\right)$ Krebs-Henseleit buffer at $37^{\circ} \mathrm{C}$. Aortic ring tension was recorded with an isometric force transducer (TRI202PAD, Panlab, ICornellà, Barcelona, Spain) and data analysed with LabChart 7 sofware (Dunedin, New Zealand). The isometric tension measurement protocol was based on a modification of a previously described technique. ${ }^{(29)}$ Briefly, mounted aortic rings were stabilised under a resting tension of $1.5 \mathrm{~g}$ during 
which time the Krebs-Henseleit buffer in the organ bath was changed every 10 minutes for 30 minutes with pre-warmed Krebs-Henseleit solution. Following this, all aortic rings were pre-contracted with phenylephrine administration $(I \mu M)$ to the organ bath until the maximum contraction tension was reached. Subsequently, aortic rings were randomly divided into groups that either received cumulative concentrations of the

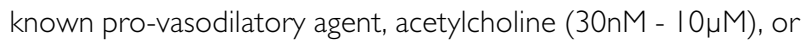
cumulative concentrations of fenofibrate $(50 \mu \mathrm{M}-125 \mu \mathrm{M})$. Pharmacological NOS inhibition was achieved by adding L-NMMA $(100 \mu M)$ to the water bath 15 minutes before the phenylephrine-fenofibrate protocol.

\section{Endothelial cell studies}

\section{Cell cultures}

Primary adult rat cardiac microvascular endothelial cells (CMECs) and aortic endothelial cells (AECs) were purchased from VEC Technologies (Rensselaer, New York, USA). CMECs and AECs were maintained in EBM-2, supplemented with 10\% feotal bovine serum, growth factors and antibiotics as per the supplier's instructions. CMEC and AEC subcultures were passaged to a maximum of 4 generations in $35 \mathrm{~mm}$ attachment factor-coated petri dishes. All cultures received fresh growth medium every second day. Endothelial cell culture purity was regularly monitored by light microscopic validation of the typical monolayer, cobblestone appearance exhibited by cultured endothelial cells $s^{(30,31)}$ as well as confirmation by flow cytometric analysis of $>80 \%$ positive staining with the endothelial cellspecific marker, acetylated low density lipoprotein labeled with I, I'-dioctadecyl-3,3,3',3'-tetramethylindo-carbocyanine perchlorate (Dil-ac-LDL; Biomedical Technologies, Stoughton, Massachusetts, USA). ${ }^{(30,31)}$ All cell cultures were grown until $100 \%$ confluency was reached for experimental purposes.

\section{Experimental conditions and procedures}

Cultured CMECs (fully confluent) were washed once with phosphate buffered saline (PBS) prior to treatment with fenofibrate or vehicle solution. Fenofibrate was dissolved in $0.2 \%$ DMSO. Cells were treated with 30 or $50 \mu$ M fenofibrate or $0.2 \%$ DMSO for I hour. Untreated, time-matched control samples received fresh medium only. In a separate set of investigations, the putative protective effects of fenofibrate pretreatment were explored in TNF-alpha-treated CMECs. Briefly, CMECs were washed once with PBS, pretreated with fenofibrate $(50 \mu \mathrm{M})$ for I hour, after which TNF-alpha (20ng/ $\mathrm{ml}$ ) was administered to the fenofibrate-pretreated cells for an additional 24 hours without changing the growth medium. Separate CMEC samples were treated with fenofibrate for 25 hours or TNF-alpha for 24 hours respectively. Control samples were incubated with growth medium, and vehicle control samples with 0.2\% DMSO (vehicle) in a time-matched fashion. After treatment, cells were washed twice with PBS and prepared for flow cytometric, Griess or Western blot analyses.

\section{Flow cytometric analyses}

Intracellular levels of $\mathrm{NO}$, superoxide and peroxynitrite were determined by flow cytometric analysis of the mean fluorescence intensity generated with the fluorescent probes: DAF-2/ DA (IO $\mu \mathrm{M}$; sensitive for $\mathrm{NO})$, DHE $(5 \mu \mathrm{M}$; sensitive for

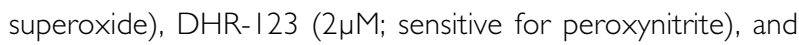
MitoSox ${ }^{T M}$ ( $5 \mu M$; sensitive for mitochondrial ROS). The flow cytometry-based assays used in this study were previously extensively characterised and validated. ${ }^{(32,33)}$ Briefly, after the respective treatment periods as described above, cultured cells were washed twice with PBS and incubated at $37^{\circ} \mathrm{C}$ for an additional 2 hours with DAF-2/DA, DHE or DHR-123, or 15 minutes with MitoSox ${ }^{T M}$ to allow the fluorescent probes to react with their respective intracellular target molecules. Following this, the fluorescent probe-containing cells were washed once with PBS and removed from culture by trypsinization. Trypsinized cells were centrifuged for 3 minutes at I 000rpm and the pellet subsequently re-suspended in PBS in preparation for flow cytometric analysis. To verify the sensitivity of the fluorescent probes for their target molecules, positive control experimental groups were included in which cells were treated with $100 \mu \mathrm{M}$ of the NO-donor, DEA/

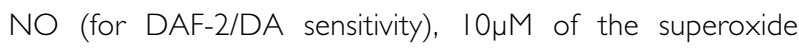

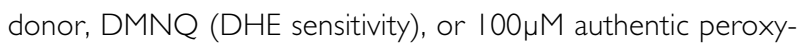
nitrite (for DHR-123 sensitivity) respectively, as previously described. ${ }^{(32-34)}$ All flow cytometric analyses were performed with a Becton Dickinson FACSCalibur ${ }^{\circledR}$ (Becton, Dickinson and Co, San Jose, California, USA) using WinMDI $^{\circledR}$ version 2.9 software (Purdue University Cytometry Laboratories, West Lafayette, USA). Acquisition was set at 10000 events/sample, and the mean fluorescence intensity of DAF-2/DA and DHE was analysed in flow channel I and flow channel 2 respectively. DHR- 123 and MitoSox ${ }^{\text {TM }}$ were analysed in flow channel 3.

Loss of cell viability was measured by means of flow cytometric analysis of propidium iodide staining according to the manufacturer's instructions. Trypsinized cells were incubated with propidium iodide for 15 minutes in the dark before flow cytometric analysis. Samples were analysed in flow channel 2 and 5000 events were acquired per sample. Data analysis was performed with WinMD|® ${ }^{\circledR}$ version 2.9 software.

\section{Plate reader analyses with the Griess Reagent}

In order to validate the results obtained with the DAF-2/DA assay, a different NO detection method, the Griess assay, was employed to measure the cellular release of nitrites (breakdown products of NO). CMECs and AECs were cultured in 24-well microplates until confluent. Cells were treated with $50 \mu \mathrm{M}$ fenofibrate in $500 \mu \mathrm{l}$ PBS for I hour, after which an equal volume of $500 \mu \mathrm{L}$ Griess reagent ${ }^{(35)}$ was added to each well. After 15 minutes incubation, the colorimetric reaction was measured at 540nM on a FLUOstar Omega platereader from BMG Labtech (Ortenberg, Germany). Serial dilutions of a nitrite 


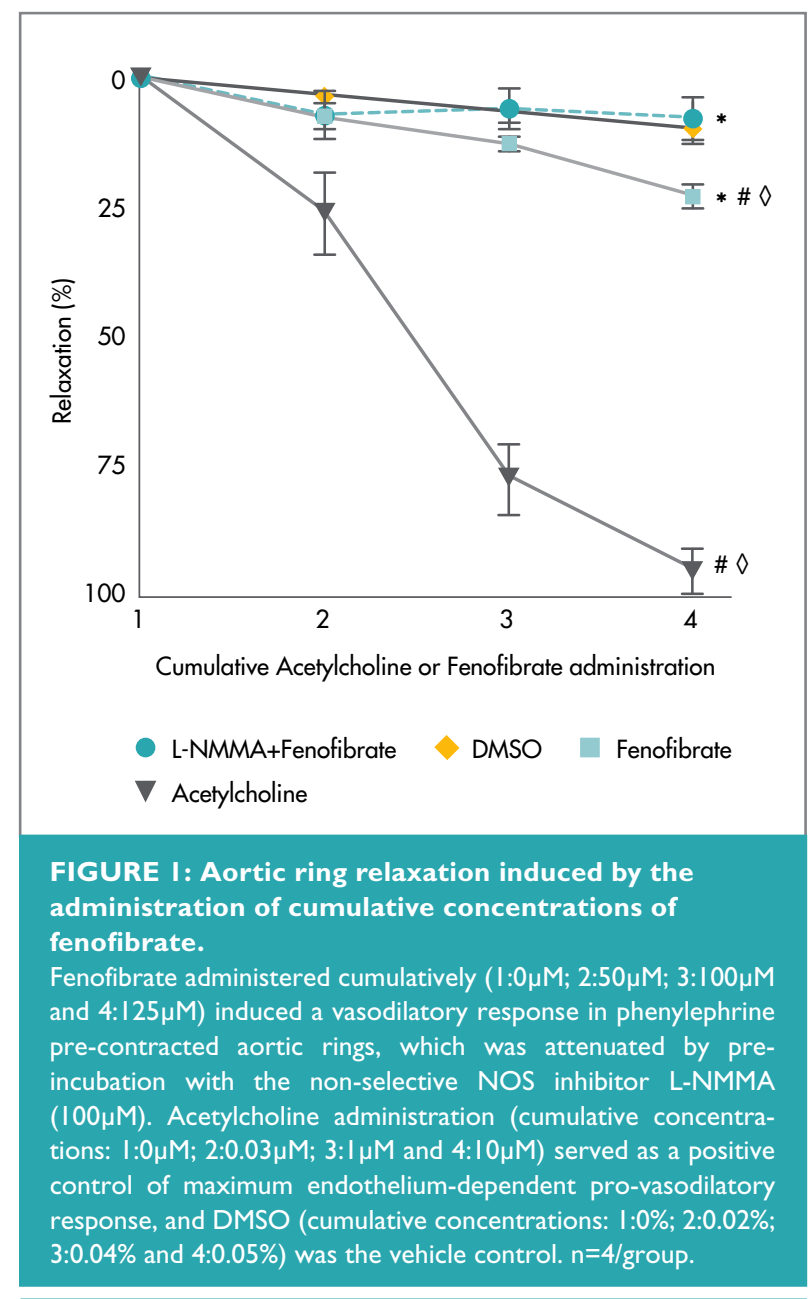

$*=p<0.05$ vs. acetylcholine, $\#=p<0.05$ vs. L-NMMA + Fenofibrate, $\diamond=p<0.05$ vs. DMSO

standard $\left(\mathrm{NaNO}_{2}\right.$ dissolved in PBS; 0 - 10 $\left.\mu \mathrm{M}\right)$ were included in each microplate to create a standard curve. Data were calculated from the standard curve and expressed as $\mu M$ nitrites.

\section{Western Blot analyses}

CMECs were lysed using a lysis buffer (20.0mM Tris- $\mathrm{HCl}$; I.0mM EGTA; 1.0mM EDTA; 150mM NaCl; $1.0 \mathrm{mM}$ $\beta$-glycerophosphate; $2.5 \mathrm{mM}$ sodium pyrophosphate; $0.1 \%$ sodiumdodecylsulphate; $1.0 \mathrm{mM}$ sodium orthovanadate; $1.0 \%$ Triton-X100; 10 $\mu \mathrm{g} / \mathrm{ml}$ leupeptin; $10 \mu \mathrm{g} / \mathrm{ml}$ aprotinin; 50nM sodium fluoride; $50 \mu \mathrm{g} / \mathrm{ml}$ phenylmethylsulfonyl fluoride) and homogenised with $0.5 \mathrm{~mm}$ zirconium beads and a Bullet Blender $^{T M}$ (Next Advance, Inc., New York, USA). Protein content was determined with the Bradford assay.(36) Equal amounts of protein $(20 \mu g)$ were separated on SDS-polyacrylamide gels and electro-transferred to a polyvinylidene difluoride membrane. Non-specific protein binding sites on the membrane were blocked with 5\% fat free milk powder, dissolved in tris buffered saline-Tween-20 (0.1\%) for I hour.
Membranes were incubated overnight with the following primary antibodies: eNOS and phosphorylated-eNOS (Ser I 177), Akt and phosphorylated-Akt (Ser 473), AMPK and phosphorylated-AMPK (Thr 172), I $\mathrm{K} \alpha$, cleaved caspase-3, nitrotyrosine and P22PHOX. The secondary antibody was horseradish peroxidase-linked anti-rabbit $\lg G$ or anti-mouse $\lg G$ and protein bands were visualised with the $\mathrm{ECL}^{\mathrm{TM}}$ chemiluminescent system. Films were densitometrically analysed (UN-SCAN-IT, Silk Scientific, Orem, UT, USA). Ponceau stains were used as loading control. The ponceau stain was densitometrically analysed and quantified. All data were then expressed as a ratio of total protein over the quantified ponceau value for that specific lane in the blot. The relative phosphorylation status of proteins was expressed as a ratio of phosphorylated over total protein expression. Membranes were stripped of primary and secondary antibodies with 0.2M $\mathrm{NaOH}$ and re-probed with a different antibody; therefore some proteins shared ponceau loading controls.

\section{Statistical analysis}

All flow cytometry data were calculated as mean \pm standard error of the mean, with values expressed as \% of control (control adjusted to 100\%). Propidium iodide data were expressed as \% change in non-viable (stained) cells compared to control (control adjusted to 100\%). Total sample sizes for the flow cytometry investigations were derived from experiments repeated at least 2 - 3 times on separate days using cells cultured from different batches (total n-values are shown below each graph). For western blot data, controls were adjusted to $\mathrm{I}$ and sample sizes were a minimum of $\mathrm{n}=3 /$ group. Student's t-tests or one-way analysis of variance (with Bonferroni multiple comparison test or Dunnet post hoc test) were used to determine statistical significance. All aortic ring isometric tension data were expressed as the \% relaxation of maximum contraction and statistically analysed by means of two-way analysis of variance followed by Bonferonni post-test. Differences with a $p$ value $<0.05$ were considered statistically significant. Data were analysed using GraphPad Prism 5 software (GraphPad Software, San Diego, California, USA). Sample sizes are indicated below each graph.

\section{RESULTS}

\section{Cumulative NOS-dependent relaxation of aortic rings}

Cumulative administration of fenofibrate induced a maximum vasodilatory response of $23 \%$ in phenylephrine pre-contracted aortic rings after 30 minutes (vs. DMSO vehicle: 10\% relaxation; $p<0.05$ ) (Figure 1). Pretreatment with the NOS inhibitor, L-NMMA $(100 \mu M)$, significantly attenuated the fenofibrateinduced relaxation from $23 \%-8 \%$ ( $p<0.05$ vs. fenofibrate), thereby confirming NOS-dependence. 


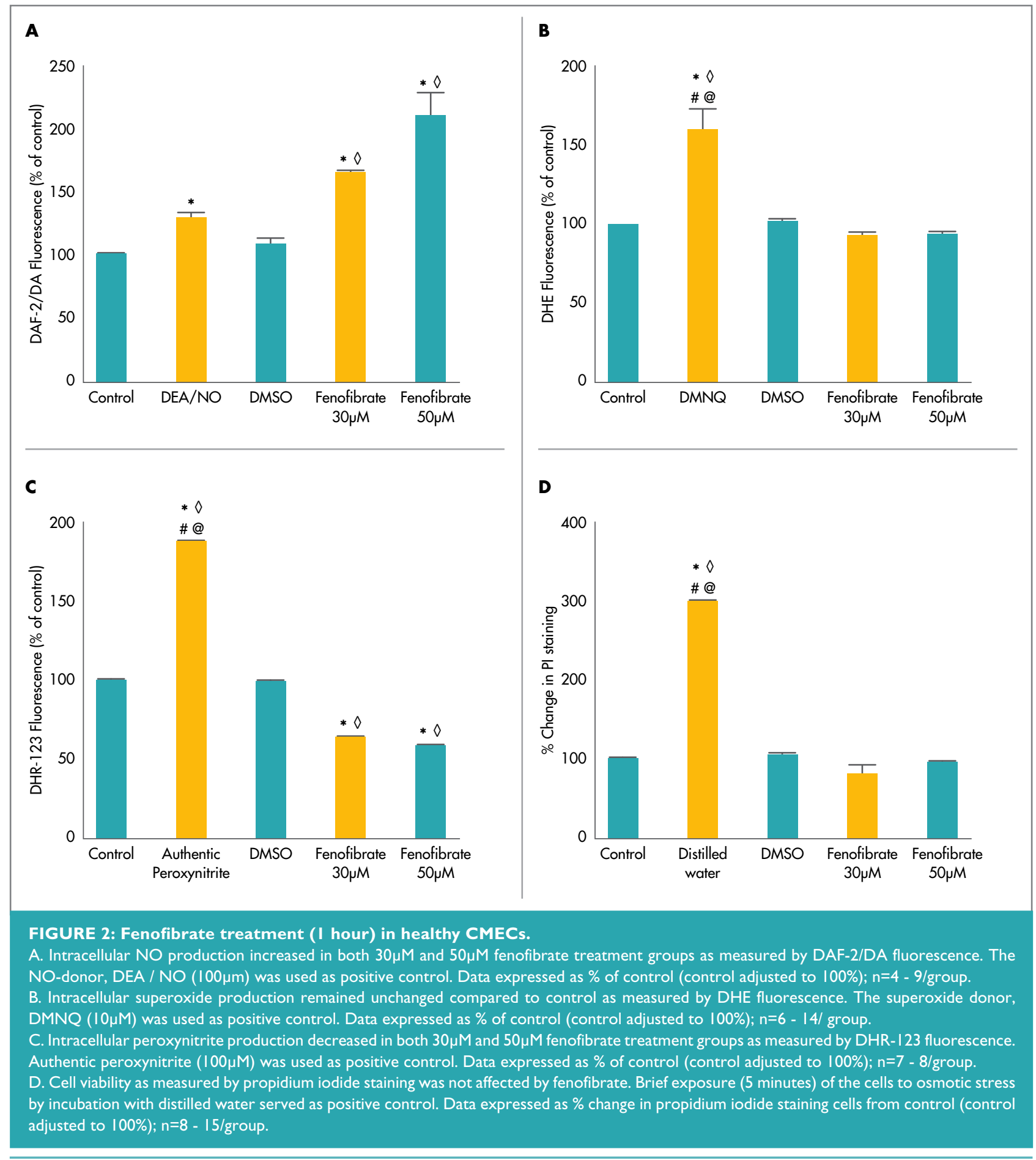

$*=p<0.05$ vs. control, $\oslash=p<0.05$ vs. DMSO, \#= $=0<0.05$ vs. fenofibrate $30 \mu \mathrm{M}, @=p<0.05$ vs. fenofibrate $50 \mu \mathrm{M}$.

\section{Fenofibrate treatment increases intracellular} NO and nitrite concentration, and decreases ROS levels, with no effect on cell viability

The NO-donor, DEA/NO significantly increased DAF-2/DA fluorescence, confirming the NO-sensitivity of the probe (Figure 2a). At I hour, both $30 \mu \mathrm{M}$ and $50 \mu \mathrm{M}$ fenofibrate increased DAF-2/DA fluorescence by 1.7-fold and 2.2-fold respectively vs. control $(p<0.05)$ (Figure $2 a)$. The superoxidedonor, DMNQ, significantly increased DHE fluorescence compared to control; however, fenofibrate exerted no effects on DHE fluorescence at either $30 \mu \mathrm{M}$ or $50 \mu \mathrm{M}$ treatment (Figure 2b). Authentic peroxynitrite significantly increased DHR-123 fluorescence compared to control. Fenofibrate treatment resulted in decreased DHR-123-fluorescence com- 
pared to control at both $30 \mu \mathrm{M}(36 \%$ decrease; $\mathrm{p}<0.05)$ and $50 \mu \mathrm{M}$ (42\% decrease; $p<0.05$ ) (Figure $2 c$ ). Cell viability in

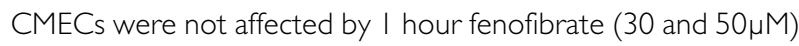
treatment (Figure 2d). DEA/NO increased the concentration of nitrites by 2 -fold compared to control $(p<0.0001)$ in CMECs (Figure 3a); similarly, I hour treatment with $50 \mu \mathrm{M}$ fenofibrate

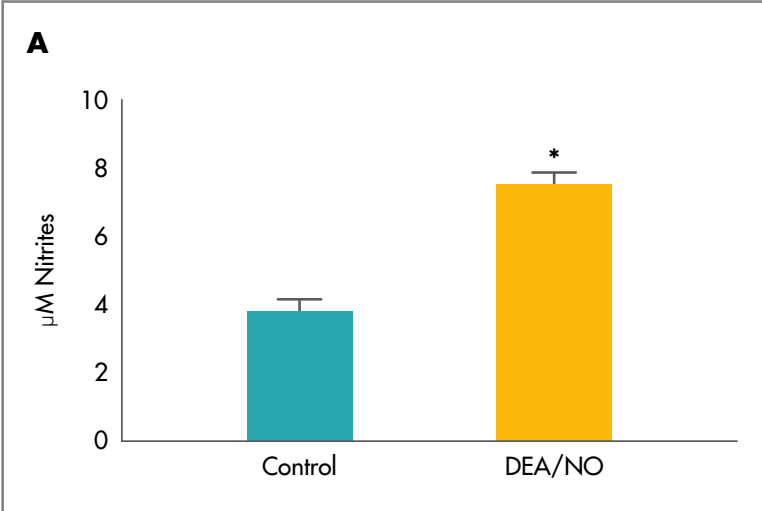

B

CMECs
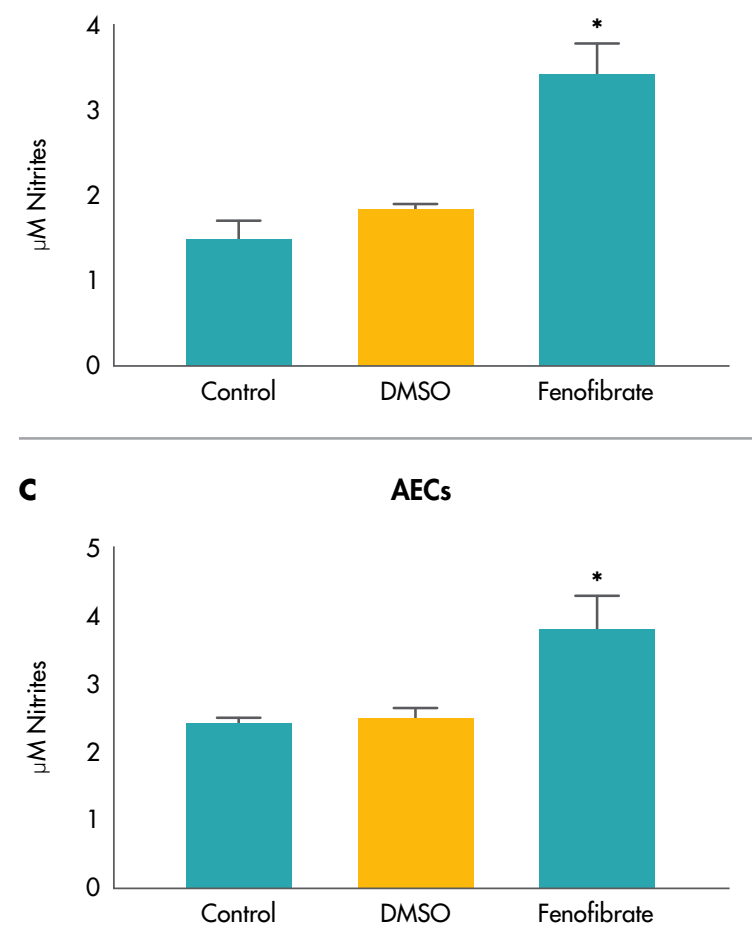

FIGURE 3: Concentration nitrites as measured by the Griess assay in CMECs and AECs.

A. DEA/NO (positive control) increased nitrite concentration in the supernatant; $n=7$ - 8 per group.

B. Concentration nitrites released into supernatant increased after I hour treatment with $50 \mu \mathrm{M}$ fenofibrate in CMECs; $n=8-13$ /group.

C. Concentration nitrites released into supernatant increased

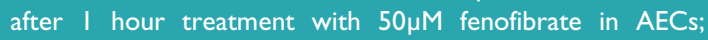
$n=8-1$ I/group.

$*=p<0.05$ vs. control. increased the concentration of nitrites by 2 -fold compared to control $(p<0.00 \mathrm{I})$ (Figure $3 b)$, and by $60 \%$ in AECs $(p<0.05)$ (Figure 3c).

Fenofibrate pre-treatment prevents TNF-alpha induced effects on NO and ROS synthesis, and prevents loss of cell viability

DAF-2/DA fluorescence measurements indicated that TNFalpha treatment (20ng/ml; 24 hours) resulted in a $17 \%$ reduction in NO-production ( $p<0.05$ vs. control) (Figure $4 a$ ), which was associated with a 2.9-fold increase in the fluorescence intensity of the mitochondrial ROS probe, MitoSox ${ }^{T M}(p<0.05$ vs. control) (Figure 4b). Furthermore, there was a 39\% increase in the non-viable (propidium iodide-staining) cells in the TNF-alpha treatment group compared to control $(p<0.05)$ (Figure 4c). Taken together, the aforementioned findings are highly suggestive of the induction of endothelial dysfunction in the TNF-alpha treated CMECs.

Fenofibrate pre-treatment $(50 \mu \mathrm{M})$ prevented the TNF-alphainduced reduction in $\mathrm{NO}$-production; in fact, $\mathrm{NO}$ measurements increased by $40 \%$ compared to TNF-alpha only treatment $(p<0.05)$ (Figure $4 a)$. In addition, there was a marked 2.5 -fold reduction in mitochondrial ROS levels in the fenofibrate pre-treatment group compared to TNF-alpha only treatment $(p<0.05)$ (Figure $4 b)$. Finally, fenofibrate pre-treatment prevented the loss of cell viability observed in the TNF-alpha only treatment group $(p<0.05)$ (Figure $4 c)$.

\section{Fenofibrate pre-treatment increases eNOS} (Ser I I77) and AMPK phosphorylation and prevents TNF-alpha-induced expression of p22PHOX and $I \kappa B \alpha$

TNF-alpha treatment was associated with a $\sim 45 \%$ reduction in eNOS expression compared to control, which was not affected by fenofibrate pre-treatment (Figures 5a, b). However, activated eNOS (phospho eNOS Ser 1 1 77 ) levels increased by $\sim 47 \%$ in the fenofibrate pre-treatment group compared to TNF-alpha treatment alone, and a $\sim 41 \%$ increase was observed in the phosphorylated / total eNOS ratio of the fenofibrate pretreatment group compared to control (Figures 5a, c, d). Although total AMPK expression was not altered in any of the groups, activated AMPK (phospho AMPK Thr 172) levels increased by $\sim 49 \%$ in the fenofibrate pre-treatment group compared to TNF-alpha treatment alone (Figures 5a, f). Akt expression, activation and phosphorylated/total Akt ratio were not affected by any of the treatment protocols (Figures $5 \mathrm{a}, \mathrm{h}$ ).

Nitrotyrosine levels were not altered in any of the groups compared to control (Supplementary Figure SI). Fenofibrate pre-treatment reduced the expression of the NADPH-oxidase subunit p22PHOX by $\sim 50 \%$ compared to TNF-alpha treat- 


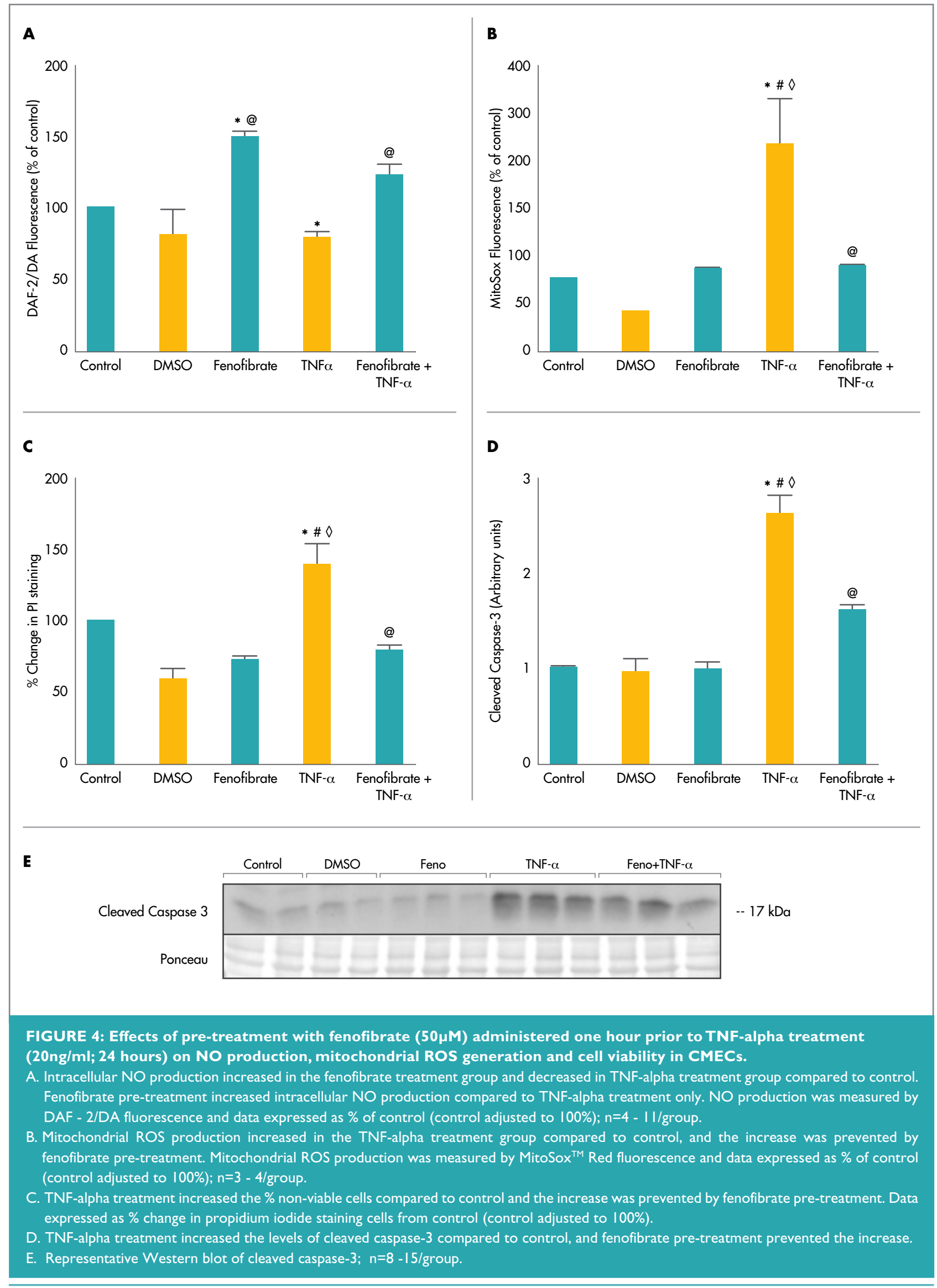

$*=p<0.05$ vs. control, $@=p<0.05$ vs. TNF- $\alpha, \#=p<0.05$ vs. DMSO, $\diamond=p<0.05$ vs. fenofibrate. Feno $=$ Fenofibrate, Feno + TNF- $\alpha=$ Fenofibrate pre-treatment. 
ment alone (Figures 6a, b). TNF-alpha treatment resulted in the activation of the NF-KB pathway as demonstrated by a decrease of $\sim 36 \%$ in the expression of $\mid \kappa B \alpha$; however, fenofibrate pre-treatment failed to prevent the reduction in $\mid \kappa B \alpha$ (Figures $6 \mathrm{a}, \mathrm{c}$ ). TNF-alpha treatment increased the expression of cleaved caspase-3 levels by $\sim 2.6$-fold compared to control, further signifying the induction of endothelial dysfunction, whilst fenofibrate pre-treatment prevented the increase in cleaved caspase-3 levels (Figures 4d, e).

\section{DISCUSSION}

In the present study, we demonstrated that fenofibrate protects endothelial cells against the harmful effects of TNF-alpha, and that the protection is associated with the up-regulation of eNOS-NO biosynthesis, reduced ROS production, and prevention of cell death.

In the baseline experiments, healthy endothelial cells responded to short term fenofibrate treatment by a marked increase in NO production. This observation was further supported by a

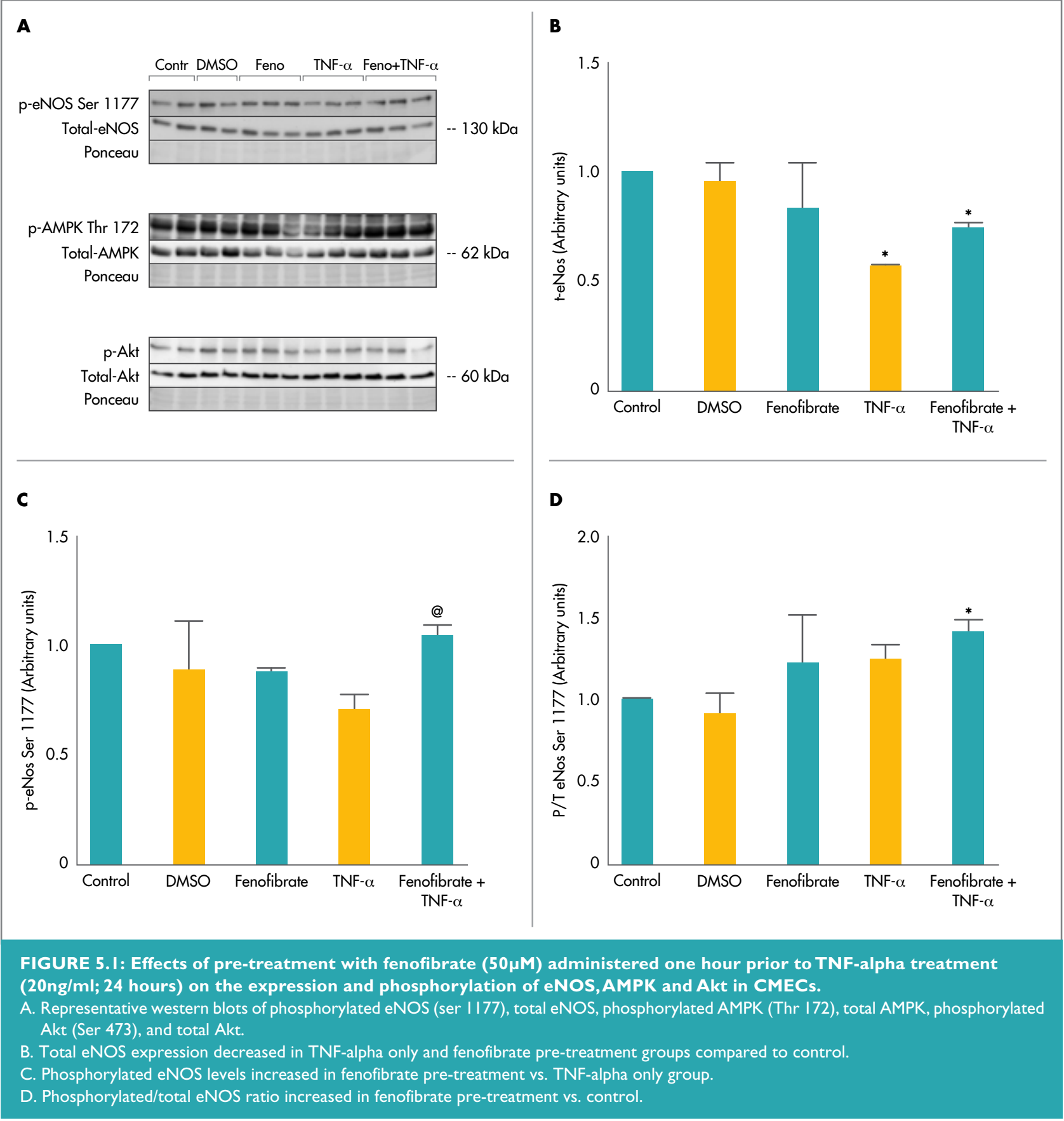

$*=p<0.05$ vs. Control. $@=p<0.05$ vs. TNF-alpha. $n=3 /$ group. Feno $=$ fenofibrate, Fenofibrate + TNF- $\alpha=$ fenofibrate pretreatment. 


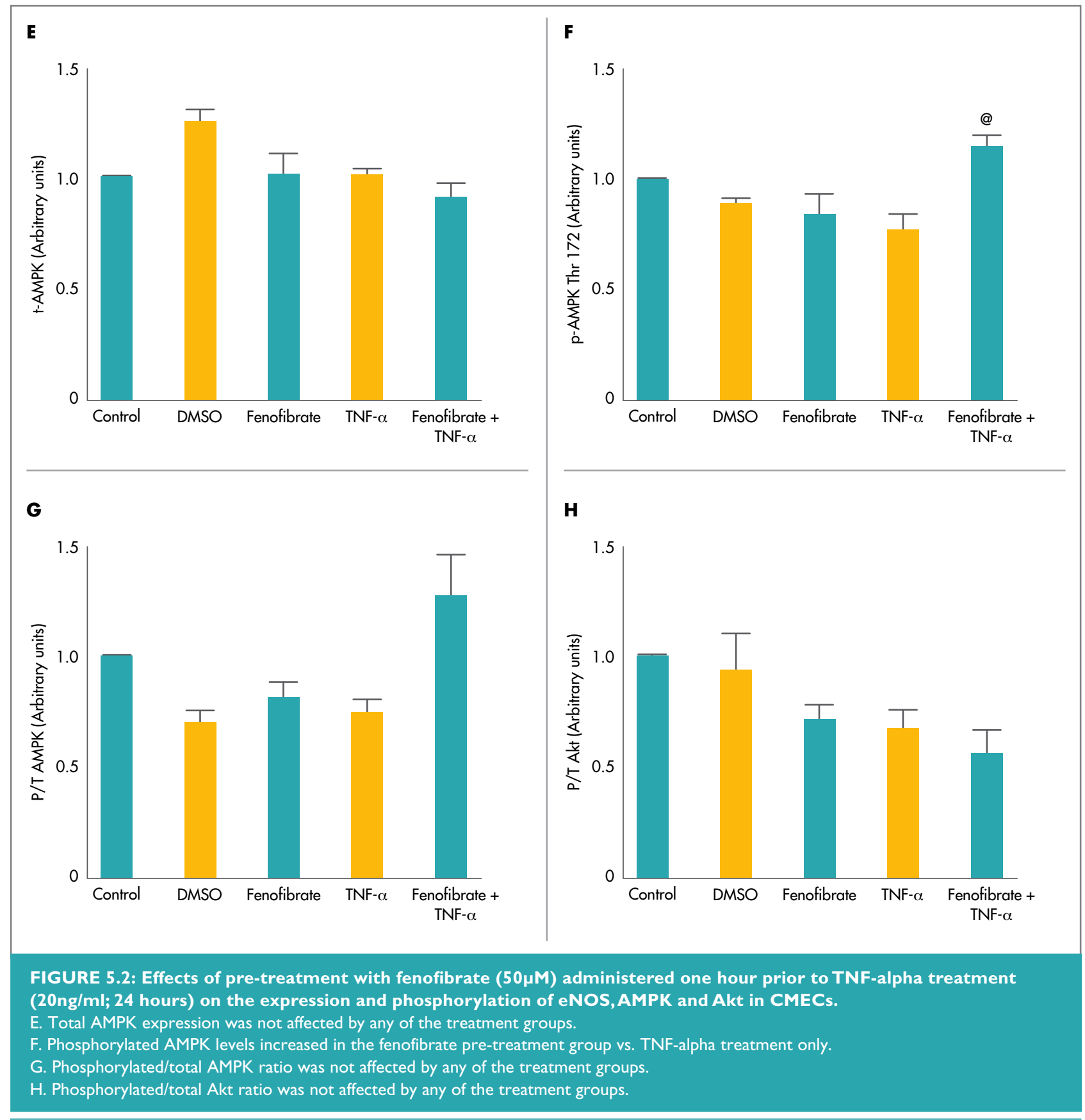

$*=p<0.05$ vs. Control. @ = p<0.05 vs. TNF-alpha. $n=3$ /group.

modest, but significant eNOS-dependent pro-vasodilatory response to fenofibrate administration in rat aortic rings. The ability of fenofibrate to increase $\mathrm{NO}$ production in endothelial cells has previously been demonstrated. For example, in cultured human umbilical vein endothelial cells (HUVECs), fenofibrate $(30 \mu \mathrm{M}$; 10 minutes) treatment resulted in a $\sim 2$-fold increase in NO production, ${ }^{(37)}$ in line with the increases observed in our study. Similarly, a 2-fold increase in NO production was observed in human glomerular microvascular endothelial cells treated with fenofibrate $(100 \mu \mathrm{M})$ for I hour..$^{(9)}$ In bovine aortic endothelial cells, fenofibrate $(50 \mu \mathrm{M})$ was shown to increase eNOS expression and activity after 48 hours treatment; however, the authors did not measure $\mathrm{NO}$ production. ${ }^{(38)}$ The general consensus in the literature that fenofibrate up-regulates $\mathrm{NO}$ biosynthesis in vascular endothelial cells has potentially important implications, as $\mathrm{NO}$ is associated with beneficial effects in the cardiovascular system via, among others, anti-inflammatory, anti-apoptotic and anti-necrotic mechanisms. ${ }^{(39)}$ In our hands, fenofibrate treatment affected neither baseline superoxide production, nor intracellular levels of the harmful radical peroxynitrite compared to control conditions, demonstrating that the large increases in $\mathrm{NO}$ 


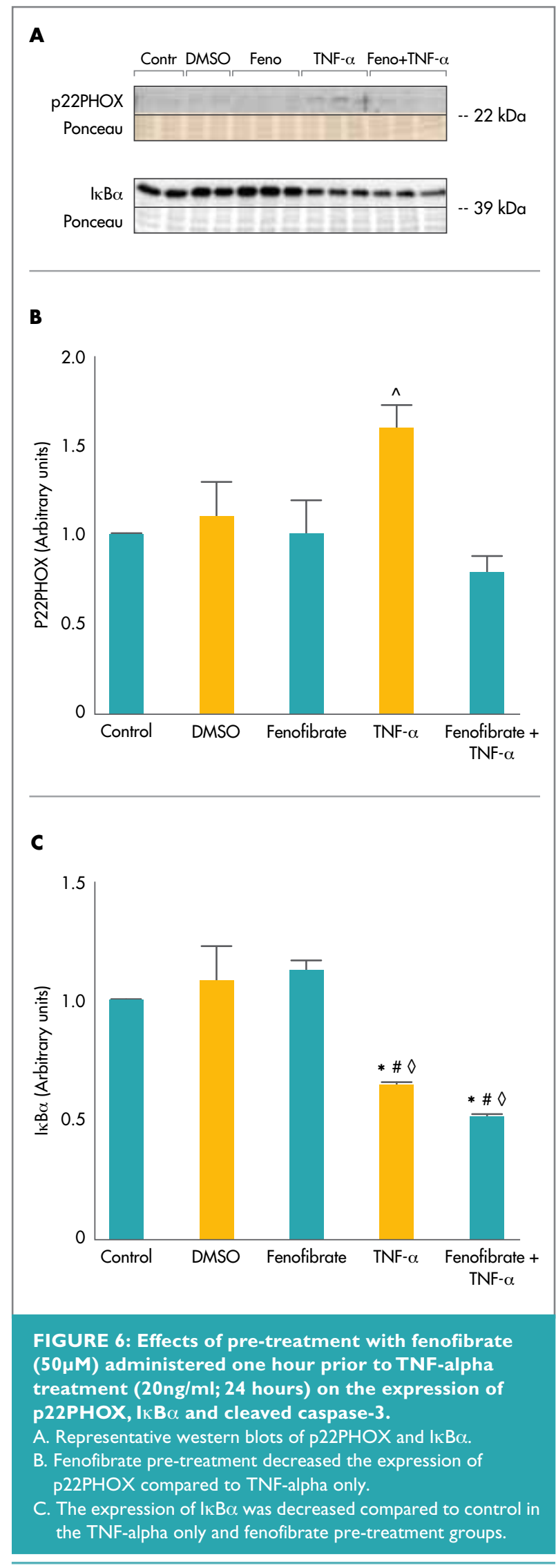

$*=p<0.05$ vs. Control. $\#=p<0.05$ vs. DMSO. $\Delta=p<0.05$ vs. Fenofibrate, $@=p<0.05$ vs. TNF-alpha. ${ }^{\wedge}=p<0.05$ vs. Fenofibrate + TNF-alpha, $n=3$ /group. Feno $=$ fenofibrate, Fenofibrate + TNF- $\alpha=$ fenofibrate pre-treatment.

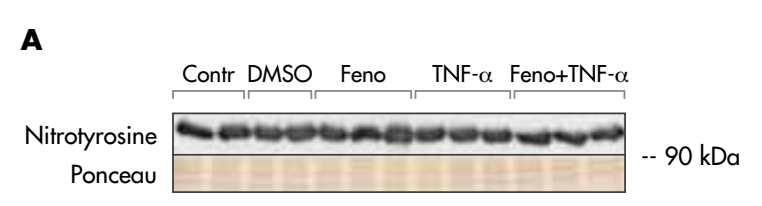

B

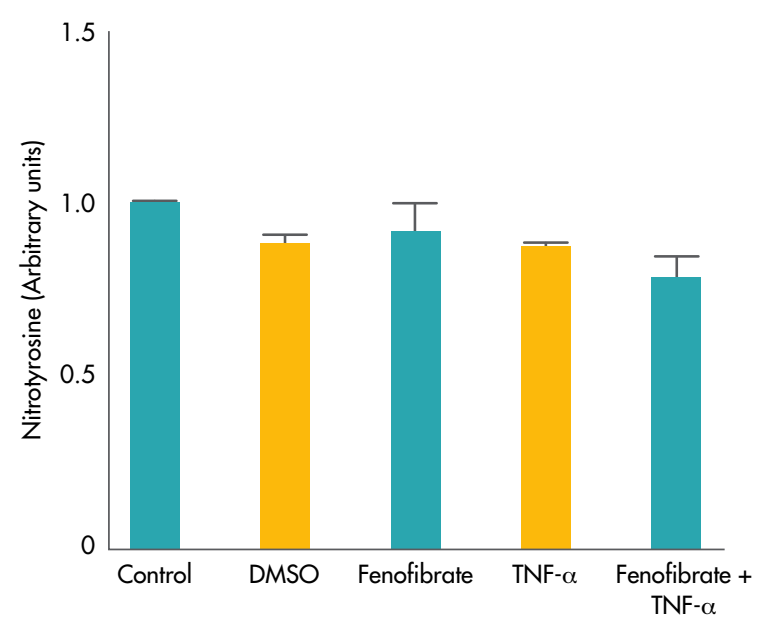

SUPPLEMENTARY FIGURE SI: Nitrotyrosine levels.

A. Representative Western blot for nitrotyrosine.

B. No changes were found in nitrotyrosine levels after DMSO, fenofibrate, TNF- $\alpha$ or fenofibrate + TNF- $\alpha$ treatment.

$n=3$ group.

production were not associated with oxidative or nitrosative stress. Cell viability remained unaffected compared to untreated control conditions.

Following the baseline studies in healthy CMECs, we investigated whether the effects of fenofibrate would translate into protection in a model of dysfunctional endothelial cells induced by a harmful inflammatory stimulus, with regards to $\mathrm{NO}$ production, ROS generation and cell viability. To our knowledge, the endothelioprotective properties of fenofibrate have not previously been demonstrated in this context. Previous data from our laboratory showed that 24 hours treatment of CMECs with TNF-alpha at $20 \mathrm{ng} / \mathrm{ml}$ resulted in endothelial dysfunction as determined by reduced $\mathrm{NO}$ production, eNOS down-regulation and increased oxidative stress. ${ }^{(40)}$ The same concentration and treatment period were used in the present study, and endothelial dysfunction was demonstrated by reduced eNOS protein expression associated with decreased $\mathrm{NO}$ levels, increased mitochondrial ROS generation, decreased cell viability and increased apoptosis. Furthermore, the proinflammatory effects of TNF-alpha were confirmed by increased NF-KB activity. In addition to our own previous findings, ${ }^{(40)}$ others have also shown that TNF- $\alpha$ down-regulates eNOS and/or reduces $\mathrm{NO}$ production in various models of endothelial 
cells. $^{(41-43)}$ Furthermore, the induction of ROS generation by TNF-alpha, ${ }^{(44,45)}$ as well as its pro-apoptotic effects ${ }^{(47,47)}$ have extensively been described.

We have demonstrated that fenofibrate pre-treatment protected the endothelial cells against the harmful effects of TNFalpha with regards to $\mathrm{NO}$ production, $\mathrm{ROS}$ generation and cell viability. The protection was characterised by the prevention of a decrease in $\mathrm{NO}$ production, the prevention of an increase in mitochondrial ROS production and p22PHOX expression, the prevention of a loss of cell viability, and the prevention of increases in cleaved caspase-3 levels. Pre-treatment of CMECs with fenofibrate resulted in increased activated eNOS (p-eNOS Ser 1 177) levels compared to cells treated with TNF-alpha only, as well as a significantly greater p-eNOS Ser I I77 / total eNOS ratio compared to untreated control. The up-regulation of eNOS activation was associated with a $\sim 40 \%$ increase in $\mathrm{NO}$ generation compared to TNF-alpha only. Indeed, many of the pleiotropic effects of fenofibrate on vascular endothelium have been attributed to eNOS phosphorylation and activation; $; 9,37,38)$ however, most studies have not investigated fenofibrateinduced effects on the eNOS-NO biosynthesis pathway in the context of injured or dysfunctional endothelial cells. AMPK and Akt are regarded as two of the most important upstream regulators of eNOS activation via Ser I I 77 phosphorylation. ${ }^{(48)}$ In the present study, fenofibrate pretreatment increased activated AMPK (phospho AMPK Thr 172) levels compared to TNF-alpha only treatment, which corresponds with the increased activation of eNOS. In this regard, fenofibrate has previously been associated with increased phosphorylation of AMPK (Thr 172) in a variety of endothelial cell types; ${ }^{(9,37,49,50)}$ however, none of these studies were conducted in the context of TNF-alpha induced injury. Tomizawa, et al. (201 I) showed that $100 \mu \mathrm{M}$ fenofibrate activates AMPK and Akt in human glomerular microvascular endothelial cells with resultant activation of eNOS (Ser I I77) within I hour of treatment. Similarly, Murakami, et al. (2006) demonstrated that fenofibrate activates AMPK and eNOS (Ser I I77) in HUVECs. These findings were observed at a concentration of $30 \mu \mathrm{M}$ at 10 minutes. Kim, et al. (2007) showed fenofibrate protects endothelial cells against apoptosis via a PPAR $\alpha$ independent, AMPK dependent activation. Although the latter study used a similar concentration of fenofibrate $(50 \mu \mathrm{M})$ compared to ours, it was performed in retinal endothelial cells and treatment lasted for I hour. From the literature, it is clear that eNOS and AMPK can be activated within minutes of stimulation. ${ }^{(37)}$ Although we did perform experiments to investigate the short term effects of fenofibrate on eNOS and AMPK activation (5, 15 and 30 minutes), no evidence of activation by phosphorylation was detected (Supplementary, Figure S2). None of the treatment protocols in the present study exerted any effects on Akt expression or activation. It therefore seems that upstream Akt played no role in the phosphorylation of eNOS in our hands. The literature appears to be contradictory regarding fenofibrate's effects on Akt; whereas some studies showed an association with increased phosphorylation of Akt (Thr 308) in human glomerular

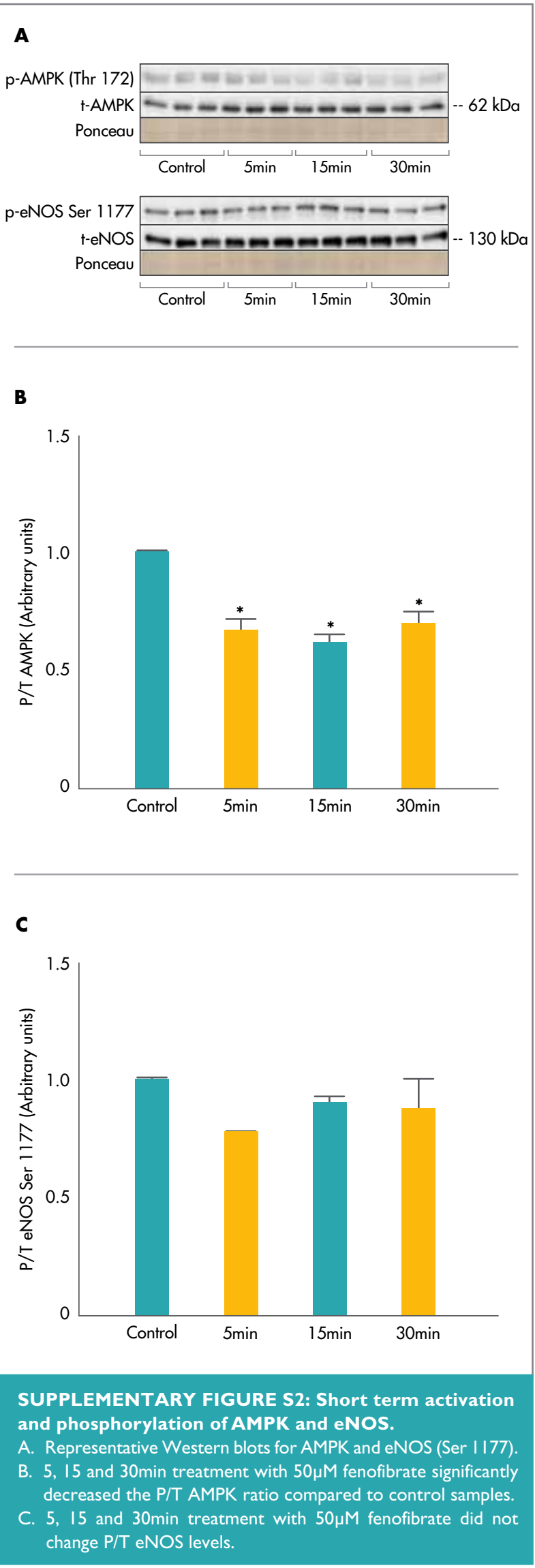

$*=p<0.05$ vs. control, $n=3$ /group. 
microvascular endothelial cells $s^{(9)}$ and Akt (Ser 473) in hepatocytes, ${ }^{(51)}$ others demonstrated inhibition of the Akt pathway in HUVECs, ${ }^{(52)}$ and hepatocytes. ${ }^{(53)}$

The induction of 2 oxidative stress markers by TNF-alpha in the CMECs (p22PHOX and mitochondrial ROS levels) was prevented by fenofibrate pretreatment. Fenofibrate's antioxidant properties have previously been demonstrated in an in vivo study by reducing superoxide anion levels and $\mathrm{p} 22 \mathrm{PHOX}$ expression in a model of nicotine-treated rat aortic tissue;; ${ }^{(54,55)}$ however the authors did not investigate the effects in endothelial cells. Although fenofibrate pretreatment did not alter TNF-alpha-induced activation of NF-KB in our hands, it was associated with a marked improvement in cell viability and reduced caspase- 3 mediated apoptosis. NO appears to have paradoxical effects on apoptosis. ${ }^{(56)} \mathrm{NO}$ can inhibit caspase-3 by s-nitrosation, ${ }^{(57)}$ and it is possible that fenofibrate resulted in reduced caspase- 3 mediated apoptosis due to increased levels of NO. Although anti-apoptotic effects of fenofibrate have previously been demonstrated in human retinal endothelial cells subjected to serum deprivation, ${ }^{(49)}$ and in HUVECs exposed to high glucose, ${ }^{(10)}$ we could not find any studies investigating the anti-apoptotic effects of fenofibrate in the context of TNFalpha induced endothelial injury. Repeating pre-treatment studies in the presence of a NOS-inhibitor would have added great value to the study, and the lack thereof is acknowledged as a shortcoming.

In conclusion, the present study provides novel data demonstrating that fenofibrate pretreatment protects adult rat endothelial cells against the harmful, pro-endothelial dysfunction effects of TNF-alpha with regards to $\mathrm{NO}$ and ROS production, and cell viability parameters. The findings are important in view of the fact that therapeutic interventions may prevent endothelial dysfunction. Inflammation has emerged as a pivotal roleplayer in the pathophysiology of arterial diseases (reviewed in 15) and therapies aimed at preventing this condition should be further researched. Although our data suggest that fenofibrate shows potential as a possible future therapeutic option in the preventative treatment of TNF-alpha-induced endothelial dysfunction, more studies are needed to further explore and validate these promising observations.

\section{FUNDING AND ACKNOWLEDGEMENTS}

The financial assistance of the National Research Foundation (NRF) (Grant number: 80570) and Harry Crossley Foundation (Stellenbosch University) towards this research is hereby acknowledged. Opinions expressed and conclusions arrived at, are those of the authors and are not necessarily to be attributed to the funding bodies. The contributions of Wiehan van Wyk and Darren Jones for their technical assistance in the laboratory are also acknowledged.

\section{Conflict of interest: none declared.}

\section{REFERENCES}

I. Kon Koh K, Yeal Ahn J, Hwan Han S, et al. Effects of fenofibrate on lipoproteins, vasomotor function, and serological markers of inflammation, plaque stabilisation, and hemostasis. Atherosclerosis. 2004; 174(2):379-383.

2. Khera AV, Plutzky J. Management of low levels of high-density lipoproteincholesterol. Circulation. 2013;128(1):72-78.

3. Wang G, Liu X, Guo Q, et al. Chronic treatment with fibrates elevates superoxide dismutase in adult mouse brain microvessels. Brain Res. 2010; | 359:247-255

4. Walker AE, Kaplon RE, Lucking SM, et al. Fenofibrate improves vascular endothelial function by reducing oxidative stress while increasing endothelial nitric oxide synthase in healthy normolipidemic older adults. Hypertension. 2012;60(6): 1517-1523.

5. Price ET, Welder G], Zineh I. Modulatory effect of fenofibrate on endothelial production of neutrophil chemokines IL-8 and ENA-78. Cardiovasc Drugs Ther. 2012;26:95-99.

6. Krysiak R. Gdula-Dymek A, Okopien B. The effect of fenofibrate on lymphocyte release of proinflammatory cytokines and systemic inflammation in simvastatin-treated patients with atherosclerosis and early glucose metabolism disturbances. Basic Clin Pharmacol Toxicol. 20 I3; I 12(3): 198-202.

7. Undas A, Celinska-Löwenhoff M, Löwenhoff T, et al. Statins, fenofibrate, and quinapril increase clot permeability and enhance fibrinolysis in patients with coronary artery disease. J Thromb Haemost. 2006;4(5): I 029- 1036.

8. Lee JJ, Jin YR, Yu JY, et al. Antithrombotic and antiplatelet activities of fenofibrate, a lipid-lowering drug. Atherosclerosis. 2009;206(2):375-382.

9. Tomizawa A, Hattori $Y$, Inoue $T$, et al. Fenofibrate suppresses microvascular inflammation and apoptosis through adenosine monophosphate-activated protein kinase activation. Metabolism. 201 1;60(4):513-522.

10. Zanetti M, Stocca A, Dapas B, et al. Inhibitory effects of fenofibrate on apoptosis and cell proliferation in human endothelial cells in high glucose. J Mol Med (Berl). 2008;86(2): 185-195.

II. Bian K, Murad F. Vascular system: Role of nitric oxide in cardiovascular diseases. J Clin Hypertens (Greenwich). 2008; 10(4):304-310.

12. Daff S. NO synthase: Structures and mechanisms. Nitric Oxide. 2010; 23(I):I-11.

13. Blake GJ, Ridker PM. Novel clinical markers of vascular wall inflammation. Circ Res. 2001;89:763-77।.

14. Ait-Oufella H, Taleb S, Mallat Z, et al. Recent advances on the role of cytokines in atherosclerosis. Arterioscler Thromb Vasc Biol. 201 I;3 I (5): 969-979.

15. Carbone F, Montecucco F. Inflammation in arterial diseases. IUBMB Life. 2015;67(1):18-28

16. Pober JS. Endothelial activation: Intracellular signaling pathways. Arthritis Res. 2002;4 Suppl 3:S109-16.

17. Ait-Oufella H, Taleb S, Mallat Z, et al. Recent advances on the role of cytokines in atherosclerosis. Arterioscler Thromb Vasc Biol. 201 1;31:969- 979.

18. Bonetti PO. Endothelial dysfunction: A marker of atherosclerotic risk. Arterioscler Thromb Vasc Biol. 2003;23(2): I68- 175.

19. Bauersachs J, Widder JD. Endothelial dysfunction in heart failure. Pharmacol Rep. 2008;60(1):119-126.

20. Brevetti G, Schiano V, Chiariello M. Endothelial dysfunction: A key to the pathophysiology and natural history of peripheral arterial disease? Atherosclerosis. 2008;197(1): I- I I.

21. Mudau M, Genis A, Lochner A, Strijdom H. Endothelial dysfunction: The early predictor of atherosclerosis. Cardiovasc J Afr 20 I 2;23(4):222-31.

22. Chen $X$, Andresen BT, Hill M, et al. Role of reactive oxygen species in tumor necrosis factor-alpha induced endothelial dysfunction. Curr Hypertens Rev. 2008;4(4):245-255.

23. Münzel $T$, Daiber $A$, Ullrich $V$, et al. Vascular consequences of endothelial nitric oxide synthase uncoupling for the activity and expression of the soluble guanylyl cyclase and the cGMP-dependent protein kinase. Arterioscler Thromb Vasc Biol. 2005;25(8): I 55 I-7.

24. Li JM, Mullen AM, Yun S, et al. Essential role of the NADPH oxidase subunit p47(phox) in endothelial cell superoxide production in response to phorbol ester and tumor necrosis factor-alpha. Circ Res. 2002;90(2):| 43-50. 


\section{REFERENCES}

25. Zhao S-p, Wu J. Fenofibrate reduces tumour necrosis factor- $\alpha$ serum concentration and adipocyte secretion of hypercholesterolemic rabbits. Clinica Chimica, 2004;347:145-150.

26. Wang W, Bai L, Qiao $H$, et al. The protective effect of fenofibrate against TNF-alpha-induced CD40 Expression through SIRT I-mediated deacetylation of NF-KB in endothelial cells. Inflammation, 20 | 4;37(I): | | 7- | 85.

27. Rong L, Jun-tian L, Wei-jie $G$, et al. Fenofibrate inhibits tumour necrosis factor-alpha-induced expression of CD40 and matric metalloproteinase in human vascular endothelial cells. J South Med Univ, 2006;26(I0): | 383-1387.

28. Huang WP, Yin WH, Chen JW, et al. Fenofibrate attenuates endothelial monocyte adhesion in chronic heart failure: an in vitro study. Eur J Clin Invest, 2009;39(9):775-783.

29. Privett $K$, Kunert MP, Lombard JH. Vascular Phenotypes: High throughput characterisation of vascular reactivity in rats conditioned on $0.4 \%$ and $4.0 \%$ $\mathrm{NaCl}$ diet. Medical College of Wisconsin 2004 (User Manual).

30. Piper HM, Spahr R, Mertens S, et al. Microvascular endothelial cells from heart. In: Piper $\mathrm{H}$, editor. Cell culture techniques in heart and vessel research. Berlin Heidelberg: Springer Verlag; 1990;pp. I58-173.

31. Nishida M, Carley WW, Gerritsen ME, et al. Isolation and characterisation of human and rat cardiac microvascular endothelial cells. Am J Physiol. 1993; 264(2 Pt 2):H639-652.

32. Navarro-Antolín J, López-Muñoz MJ, Klatt P, et al. Formation of peroxynitrite in vascular endothelial cells exposed to cyclosporine A. FASEB J. 200I; I5(7): | $291-1293$

33. Strijdom $\mathrm{H}$, Jacobs $\mathrm{S}$, Hattingh $\mathrm{S}$, et al. Nitric oxide production is higher in rat cardiac microvessel endothelial cells than ventricular cardiomyocytes in baseline and hypoxic conditions: A comparative study. FASEB J 2006; 20(2):314-316.

34. Strijdom $\mathrm{H}$, Muller $\mathrm{C}$, Lochner A. Direct intracellular nitric oxide detection in isolated adult cardiomyocytes: Flow cytometric analysis using the fluorescent probe, diaminofluorescein. J Mol Cell Cardiol. 2004;37(4):897-902.

35. Green LC, Wagner DA, Glogowski J, et al. Analysis of nitrate, nitrite, and (I5N)nitrate in biological fluids. Anal Biochem. 1982;126(1): 131-138.

36. Bradford M. A Rapid and sensitive method for the quantitation of microgram quantities of protein utilising the principle of protein-dye binding. Anal. Biochem, 1976;72:248-254

37. Murakami H, Murakami R, Kambe F, et al. Fenofibrate activates AMPK and increases eNOS phosphorylation in HUVEC. Biochem Biophys Res Commun. 2006;34I (4):973-978.

38. Goya K, Sumitani S, Xu X, et al. Peroxisome proliferator-activated receptor alpha agonists increase nitric oxide synthase expression in vascular endothelial cells. Arterioscler Thromb Vasc Biol. 2004;24(4):658-663.

39. Lei J, Vodovotz Y, Tzeng E, Billiar TR. Nitric oxide, a protective molecule in the cardiovascular system. Nitric Oxide. 2013;35:175-85.

40. Genis A, Smit S, Westcott C, et al. Attenuation of eNOS-NO biosynthesis, up-regulation of antioxidant proteins and differential protein regulation in TNF-alpha treated cardiac endothelial cells: Early signs of endothelial dysfunction. In: Keaton TH, (editor). Endothelial Dysfunction: Risk factors, role in cardiovascular diseases and therapeutic approaches. New York: Nova Science Publishers. 2014:pp. 169-204.

41. Goodwin BL, Pendleton LC, Levy MM, et al. Tumour necrosis factor- $\alpha$ reduces argininosuccinate synthase expression and nitric oxide production in aortic endothelial cells. Am J Physiol Heart Circ Physiol. 2007:293: HIII5-HII2I.

42. Zhang J, Patel JM, Li YD, et al. Proinflammatory cytokines downregulate gene expression and activity of constitutive nitric oxide synthase in porcine pulmonary artery endothelial cells. Res Commun Mol Pathol Pharmacol. 1997;96:7|-87

43. Seidel M, Billert H, Kurpisz M. Regulation of eNOS expression in HCAEC cell line treated with opioids and proinflammatory cytokines. Kardiol Pol. 2006:64:153-158

44. Corda S, Laplace C, Vicaut E, et al. Rapid reactive oxygen species production by mitochondria in endothelial cells exposed to tumor necrosis factor-alpha is mediated by ceramide. Am J Respir Cell Mol Biol. 200 I;24:762-768.
45. Zhang $\mathrm{H}$, Park $\mathrm{Y}, \mathrm{Wu}$ J, et al. Role of TNF-alpha in vascular dysfunction. Clin Sci (Lond.). 2009; I 16(3):219-230

46. Polunovsky VA, Wendt $\mathrm{CH}$, Ingbar $\mathrm{DH}$, et al. Induction of endothelial cell apoptosis by TNF alpha: Modulation by inhibitors of protein synthesis. Exp Cell Res. 1994;214(2):584-594.

47. Gaur U, Aggarwal BB. Regulation of proliferation, survival and apoptosis by members of the TNF superfamily. Biochem Pharmacol. 2003;66(8): 1403-8.

48. Qian J. Fulton D. Post-translational regulation of endothelial nitric oxide synthase in vascular endothelium. Front Physiol 2013;4:347.

49. Kim J, Ahn JH, Kim JH, et al. Fenofibrate regulates retinal endothelial cell survival through the AMPK signal transduction pathway. Exp Eye Res. 2007; 84(5):886-893.

50. Omae T, Nagaoka T, Tanano I, et al. Fenofibrate, an anti-dyslipidemia drug, elicits the dilation of isolated porcine retinal arterioles: Role of nitric oxide and AMP-activated protein kinase. Invest Ophthalmol Vis Sci. 2012; 53(6):2880-2886

5I. Huang Z, Zhou X, Nicholson AC, et al. Activation of peroxisome proliferator-activated receptor-alpha in mice induces expression of the hepatic low-density lipoprotein receptor. Br J Pharmacol. 2008; I 55(4):596-605.

52. Goetze S, Eilers F, Bungenstock $A$, et al. PPAR activators inhibit endothelial cell migration by targeting Akt. Biochem Biophys Res Commun. 2002;293(5): | 43|- | 437.

53. Kubota T, Yano T, Fujisaki K, et al. Fenofibrate induces apoptotic injury in cultured human hepatocytes by inhibiting phosphorylation of Akt. Apoptosis. 2005; 10(2):349-358.

54. Kaur J, Reddy K, Balakumar P. The novel role of fenofibrate in preventing nicotine- and sodium arsenite-induced vascular endothelial dysfunction in the rat. Cardiovasc Toxicol. 20 I0; 10:227-238.

55. Chakkarwar VA. Fenofibrate attenuates nicotine-induced vascular endothelial dysfunction in the rat. Vasc Pharmacol. 2011;55:163-168.

56. Dimmeler S, Zeiher AM. Nitric oxide and apoptosis: Another paradigm for the double-edged role of nitric oxide. Nitric oxide, 1997; I (4):375-81.

57. Rössig L, Fichtlscherer B, Breitschopf K, et al. Nitric oxide inhibits caspase-3 by S-nitrosation in vivo. J. Biol. Chem, 1999;274:6823-6826. 